\title{
A HERMENÊUTICA CRÍTICA DE PAUL RICEUUR POSTA À PROVA DA IMAGINAÇÃO FEMININA
}

\author{
Cristina Henrique da Costa \\ cristina@iel.unicamp.br
}

\section{INTRODUÇÃO}

Como venho tentando mostrar nos últimos anos, o caráter invasivo das teorias literárias é um fenômeno multiforme: pode estar no estruturalismo de Lévi-Strauss, por exemplo, quando ele lêo mito de Édipo em L’Anthropologie Structurale. Na leitura estruturalista de Lévi-Strauss, segundo Ricœur, não só ocorre uma redução das diversas narrativas do mito de Édipo à pobreza de certas estruturas básicas, como também há um trabalho de ocultação da dimensão estética excepcional de certa obra, a tragédia de Sófocles, a qual, inspirada nas diversas versões do mito, não deve, contudo, ser igualada ao resto como se fosse tudo uma só e mesma coisa. Ainda segundo Ricœur, da redução estruturalista do conteúdo semântico das narrativas decorre a ocultação do valor estético de ÉdipoRei, fato que, aliás, já caracterizava o próprio tratamento psicanalítico da obra por Freud.

Entretanto, a atitude invasiva situa-se também e inversamente em leituras fortemente marcadas pelo historicismo estético-filosófico, como as que reduzem uma obra ao seu momento histórico - fato que por outras vias acaba impedindo paradoxalmente de ter qualquer relação estética com obras do passado. O caso limite de Homero foi discutido por Jauss em 
Pour une esthétique de la réception, (capítulo 1, L'histoire de la littérature) sob a forma da seguinte pergunta: se Homero não passasse de reflexo de um estágio de evolução social há muito ultrapassado, como poderia ainda proporcionar prazer estético?'

Em meio às armadilhas conceituais, teóricas e filosóficas que podem se esconder por trás de teorias que ditam "por fora" o que a literatura deve ser "por dentro", e cuja doxa oscila entre marxismo, estruturalismo e heideggerianismo, Paul Ricœur legou ao mundo uma obra de reflexão avessa aos excessos das afirmações teóricas insustentáveis na prática histórica e literária.

Em Tempo e narrativa (2010), a necessidade de lidar com a história significa, ao mesmo tempo e dialeticamente, o reconhecimento de sua produtividade intersubjetiva e o reconhecimento da singularidade temporal dos objetos nela produzidos subjetivamente. Neste arcabouço, encontram-se bases filosóficas para argumentar contra os dois extremos das teorias literárias invasivas referidas acima, na medida em que Ricœur preocupa-se, por um lado, com:

1) limitar o caráter redutor das assertivas estruturalistas, mostrando que a dimensão narrativa do texto de ficção, responsável pela diversidade das histórias, é um elemento de singularização semântica irredutível que opera dentro e fora dos textos ${ }^{2}$. Ricœur mostra que se as narrativas são diversas, é porque respondem a tempos históricos diversos, e sua diversidade é um fenômeno transhistórico de organização das ações humanas a partir do qual se criam as respostas, múltiplas, às aporias e aos mistérios insondáveis da condição temporal. Não há como, nem há que reduzir a multiplicidade narrativa, a qual, nesta perspectiva, configurase como o elemento fundamental de resistência do literário e do mítico contra a redução teórica e conceitual.

E por outro lado, preocupa-se também com:

2) Acolher a dimensão estética das produções e obras da cultura humana, tornando-se capaz de justificar filosoficamente a estabilidade do sentido das obras e textos. Sem dúvida, a justificativa filosófica ricœuriana

${ }^{1}$ Note-se que não estão excluídas desta categoria historicista as leituras que reduzem uma obra ao nosso momento histórico, nem mesmo as que clamam pela falência contemporânea das normas enquanto nova figura do normativo contemporâneo.

${ }^{2}$ Cf. "Imaginação, leitura e crítica" (Costa, 2015), no qual o problema retórico da delimitação do fora e do dentro do texto foi discutido. 
fundamenta-se na tradição kantiana do juízo estético reflexivo, condição de possibilidade de nossa sociabilidade intersubjetiva, embora o sujeito de Ricœur não profira juízos sobre o belo diante das obras da natureza e da cultura, e se contente com extrair de narrativas modelos de ação aproveitáveis para sua vida prática e aplicáveis ao seu momento histórico de leitor ${ }^{3}$. Belas são as ações e respostas humanas louváveis contra a passividade do tempo: agir é criativo, e por isso mesmo solidário de sua representação linguageira, resolvendo para Ricœur o problema de saber se a verdade da ação está exclusivamente dentro ou fora de um texto. O sujeito de Ricœur, embora não esteja de posse de regras imutáveis, reconhece seus modelos relativamente estáveis através das estruturas narrativas do que lê, enquanto paralelamente os textos produzem sentido ao longo de uma sucessão histórica4 .

Ricœur responde, portanto, a esta dupla preocupação: limitar os poderes do estruturalismo, por um lado, e garantir a relativa estabilidade dos valores práticos e poéticos, por outro lado - e nesta segunda etapa, pensar certa transhistoricidade dos valores que não seja nem fruto de uma história totalmente racional, nem resultado de uma história apenas empírica. Partidário de uma hermenêutica crítica, o filósofo reconhece que a interpretação existencial nunca é alvo de uma vivência fenomenológica direta, e precisa sempre passar pela mediação das obras produzidas ao longo do tempo. Os objetos que a história produz - técnicas, ciências, religiões, mitos, textos, documentos, marcas, obras, arquivos, ações e pensamentos, inclusive os históricos - nada deixa de ter certo grau de quase objetividade que resiste ao ser questionador que se interpreta imperfeitamente através deles.

Quando aplicada ao domínio específico da leitura de literatura, a hermenêutica crítica de Paul Ricœur, antes mesmo de qualquer discussão

\footnotetext{
${ }^{3}$ Nisto consiste a diferença fundamental entre Ricœur e Bachelard.

${ }^{4}$ Tanto Ricœur quanto Bachelard são fiéis ao princípio kantiano. Embora haja juízo estético, não pode haver conceito do Belo, e no fundo esta dupla condição crítica do estético é a única garantia que temos contra a violência teórica, tanto estruturalista quanto historicista. Embora não tenha sido pensada como questão de teoria literária, a categoria prático-poética de narrativa incorpora e leva adiante a preocupação crítica de Kant: nem empirismo, nem dogmatismo. As garantias que tenho do valor superior de Shakespeare não são empíricas (ao contrário do que dizia Johnson), ou seja, não são suscetíveis de desconstrução cética ou de redução pela crítica ideológica. Também não são teóricas, ou seja, não bloqueiam, não censuram nem impedem que eu ultrapasse Shakespeare e crie outra coisa. As razões estéticas são humanas, e subjetivas no sentido de transhistóricas e intersubjetivas.
} 
aprofundada, oferece, portanto, a possibilidade de pensar dialeticamente a leitura. Primeiro, porque é como dialética que se encontram e se desencontram numa obra, a montante, as discussões de autores/leitores com suas heranças, e a jusante, os esboços esquemáticos dos quais autores/leitores podem lançar mão para aplicar criativamente, no plano prático e poético, as verdades daquela obra, vivendo-a e vivendo-se nela. Neste sentido, e contrariando as leis habituais da estética moderna do hermético e do inutilizável, para Ricœur não há incompatibilidade entre qualidade estética e utilização de uma obra, na medida em que a própria ideia de utilização de uma obra está pensada no plano da coerência de uma filosofia hermenêutica prática. As obras são exemplos e modelos de ação, de identificação e de redescrição do real, e por isso são faláveis e usáveis.

Nesta perspectiva, entrando agora no cerne da questão deste artigo, a literatura de mulher, enquanto diálogo crítico com a tradição que precisa ao mesmo tempo situar-se historicamente e libertar-se do fado das teorias invasivas para alcançar pensar a sua própria qualidade estética no plano de suas aplicações prático-poéticas, encontra na hermenêutica crítica de Ricœur um aliado.

Entretanto, é preciso antes notar que, do ponto de vista do imenso esforço de crítica realizado por mulheres na esfera do pensamento sobre a literatura, é mais fácil enveredar pelo atalho da crítica das ideologias, para denunciar pura e simplesmente melhor do que Ricœur os postulados androcêntricos da teoria literária. Deixando claro que não estou falando de autores de literatura, e sim de teorias da literatura, pode-se por exemplo dizer que:

1) o autor genial da modernidade sempre é homem branco de cultura europeia. Mulheres, enquanto mulheres, vêm em segundo lugar. Vista desta forma, a dessacralização dos clássicos pelos modernos, com suas subsequentes delimitações rigorosas dos espaços literários entre o novo cânone (composto por obras revolucionárias ou visionárias, que nos leem antes que as leiamos) e o antigo (composto por obras que propõem ingênua e ideologicamente valores ora ultrapassados), estas delimitações, portanto, podem ainda ser caracterizadas como disputa de cavaleiros pela liderança do sagrado. Como ensina a retórica: só se discute a partir daquilo que não se discute. 
2) O momento histórico da obra raramente foi favorável às mulheres, e esta verdade fatual justifica amplamente que as mulheres se concentrem na tarefa de crítica das ideologias que imperam e governam o momento histórico.

3) o estruturalismo (em suas múltiplas formas, inclusive pós-modernas e pós-estruturalistas), ao negar a especificidade da produção de sentido própria à literatura, acaba privando os estudos feministas de um imenso campo de representação do feminino onde as mulheres possam se reconhecer livremente.

Se tais argumentos feministas precisam ser levados em consideração, inclusive porque, caso não o sejam, farão pesar sobre minha argumentação a suspeita de falar das mulheres sem dar voz às mulheres ${ }^{5}$ - e até onde sei, Ricœur não era mulher, e sequer se interessou pela definição da identidade feminina -, a questão é partir da hipótese que a crítica feminista das ideologias literárias também opera por redução do campo literário, e neste sentido precisa do apoio de uma hermenêutica para ser capaz de juízo estético. É exatamente este ponto de partida que justifica, ao meu ver, a aproximação que tento neste artigo entre a hermenêutica crítica ricœuriana e a literatura de mulher.

\section{VANTAGENS DA HERMENÊUTICA CRÍTICA DE RICGEUR}

Começo pelo mais simples: sem dúvida é preciso escolher, hoje e ontem, entre as mulheres da literatura. Mas esta escolha precisa ser uma escolha de mulher, e para tanto precisa assumir uma perspectiva hermenêutica que aplique claramente modelos de ação e identificação, os quais, embora não sejam neutros e não se meçam pelas idealidades estéticas recortadas no céu da neutralidade sexual que nada mais é para a crítica feminista que projeção androcêntrica, tampouco podem se perder no discurso de afirmação da diferença e da alteridade. Como mostrou Simone de Beauvoir, diferença e alteridade devem ser apenas pontos de partida, situações, ou em termos ricœurianos, integram o campo da prefiguração da narrativa, da leitura e da interpretação existencial.

${ }^{5}$ Fenômeno bem conhecido de dupla ocultação: pretende-se ou declara-se falar daquilo mesmo de que não se fala. 
Ora, na medida em que trabalha com o distanciamento do sentido pelo próprio desvio do texto, Ricœur oferece uma possibilidade interessante de relacionamento feminino com os textos e valores da cultura, aos quais nem totalmente damos nossa adesão (pois eles precisam ser analisados em sua ideologia) mas que também não rejeitamos totalmente (pois, do contrário, como construiríamos um campo de valores comuns?). Vejo nisso a grande vantagem do juízo hermenêutico de Ricœur: com a dialética da suspeita e da recolecção, uma feminista não é obrigada a rejeitar totalmente os textos de homens que a tradição lhe oferece, nem tampouco é obrigada a eleger os maus textos de mulher que um feminismo de pernas curtas desejaria que ela acolhesse. Neste sentido, as categorias ricœurianas de prefiguração, configuração e refiguração do texto resolvem um falso problema, permitindo mostrar que a identificação da leitora não é diretamente com a autora, sequer com a personagem feminina, e sim com a possibilidade de refigurar femininamente e por aplicação analógica aquilo que o texto traz em sua configuração, ela mesma sustida pela verossimilhança de certa prefiguração que também pode ser feminina. $\mathrm{O}$ que remete o problema da identidade para o campo da prática existencial da leitora onde está em jogo sua própria identidade narrativa. A julgar pelas conclusões filosóficas de Ricœur no capítulo 4 de Tempo e Narrativa 3, trata-se de um trabalho dialético que renova o pensamento sobre o que vem a ser a imaginação:

Quando o leitor submete suas expectativas às que o texto desenvolve, ele irrealiza a si mesmo na mesma proporção da irrealidade do mundo fictício para o qual emigra; a leitura torna-se então um lugar igualmente irreal onde a reflexão faz uma pausa. Em contrapartida, quando o leitor incorpora consciente ou inconscientemente, pouco importa - os ensinamentos de suas leituras à sua visão de mundo, para aumentar sua legibilidade prévia, a leitura é para ele algo diferente de um lugar onde ele para; ela é um meio que ele atravessa. (2010, p. 308)

Pois, de fato, o conceito de identidade narrativa de Ricœur surge da necessidade de entrecruzar narrativas históricas e narrativas ficcionais, ambas com pretensões de redescrever o real do leitor, e ambas vindo nutrir sua identidade individual, ela mesma narrativa. Em outras palavras, leio para compreender-me como mulher, e leio porque compreendo-me como mulher. E compreender-me como mulher, se eu entendi bem a proposta de Ricœur, significa implementar em todos os planos do processo hermenêutico as dialéticas do distanciamento e da apropriação: recoleção 
e suspeita; ideologia e utopia; subjetividade e objetivação através das quais lido com a diversidade da literatura e com o imaginário social.

Embrenho-me agora pelo mais complexo: resta pensar o interesse da hermenêutica crítica de Paul Ricœur para a literatura de mulher não apenas por suas virtudes hermenêuticas gerais, e sim para questionar mais a fundo a possibilidade de uma prática de mulher leitora concreta que precise da proposta ricœuriana, e não apenas se inspire vagamente nela. Nesta perspectiva, se é verdade que não há como compreender-se diretamente, sem a mediação quase objetiva dos textos e obras através dos quais nós nos entendemos, isto me soa como um convite do filósofo para que façamos a hermenêutica crítica de seu próprio texto. Ou seja, a produtividade da leitura de Ricœur para a compreensão da identidade feminina precisa passar pela discussão, com Ricœur, no terreno de minhas próprias injunções prático-poéticas - e no caso deste artigo, são injunções necessariamente feministas. Em outras palavras, aplique-se a Ricœur a própria lógica da recoleção e da suspeita.

Isto significa que sou grata a Ricœur por permitir mostrar que a identidade depende de um acervo de obras e produções das quais e nas quais seres falantes se falam e narram para poderem agir reconhecendose, - e por isso pode-se dizer hoje a partir dele que a questão feminina, de caudalosa criatividade prática e poética, está longe de ser apenas um caso específico de estudos culturais -, mas sou também obrigada a constatar que Ricœur, em suas numerosas explorações e confrontações hermenêuticas, não levou em conta a importância do desafio hermenêutico feminista, tanto para a compreensão de obras e textos da tradição, quanto para a compreensão da tarefa filosófica de decifração dos símbolos que as produções culturais enfeixam. Este desafio hermenêutico feminista, posso defini-lo tanto no plano da leitura de literatura, no qual ele se revela como drama da escolha de leitura, quanto no plano da filosofia hermenêutica, no qual ele toma a forma de um drama da ocultação simbólica no próprio âmago da reflexão sobre o símbolo.

Para delinear estes dramas, proponho implementar certa análise da prática interpretativa concreta de Ricœur à luz de outra prática hermenêutica crítica, feminista. 


\section{NECESSIDADE DE UMAHERMENÊUTICACRÍTICAFEMINISTA}

Num primeiro tempo, retornando ao momento ricœuriano de descoberta da necessidade da hermenêutica em $A$ simbólica do mal (cujos prolongamentos estão em $O$ conflito das interpretações, especialmente no capítulo Existência e hermenêutica), tenciono situar o papel da hermenêutica crítica feminista quando confrontada com a de Ricœur.

Comoésabido, a descoberta do caráter incontornável da hermenêutica relaciona-se com a constatação, pelo filósofo, da impossibilidade, para a filosofia, de dar conta direta e fenomenologicamente do mal, cuja existência proteiforme manifesta-se em nossas inumeráveis narrativas míticas, bíblicas e literárias. Como se sabe também, a virada hermenêutica de Ricœur constitui uma clara réplica à filosofia heideggeriana, como se lê, ainda, na célebre fórmula c'est seulement dans un conflit des herméneutiques rivales que nous apercevons quelque chose de l'être interprété. Em outras palavras, para Ricœur, não há reversão ontológica direta do modo de ser ao modo de compreender: jamais serei totalmente o que compreendo ser, assim como jamais compreenderei totalmente o que sou. Ou ainda, claramente: não há ontologia direta, nem há ontologia separada.

Ora, se por um lado, podemos pensar que a proposta contém com justeza certa vivência do feminino, justamente porque apenas hermenêuticas rivais em conflito serão capazes de conduzir o ser interpretante feminino a algo do ser interpretado, por outro lado, a própria necessidade de uma hermenêutica crítica assim definida fundamentase geneticamente em certa ocultação da possibilidade de interpretação feminina do campo do simbólico.

Isto fica claro na segunda parte de $A$ simbólica do mal (intitulada Os mitos do princípio e do fim), e mais exatamente no capítulo III: $O$ mito "adâmico" e a visão "escatológica" da história. Ricœur dedica-se ali a uma análise interpretativa do pecado original:

É a infinidade do próprio desejo, é o desejo do desejo que se apodera do conhecer, do querer, do fazer e do ser (...) é em relação a este "desejo" que a finitude é insuportável, essa finitude que consiste simplesmente em ser criado; a alma da interrogação da serpente é o "mau infinito" que perverte, simultaneamente, o sentido do limite que orientava a liberdade e o sentido próprio da finitude dessa liberdade orientada assim pelo limite. (2013, p. 272) 
Surge então nesta parte do texto, como é legítimo, uma interrogação hermenêutica quanto ao papel simbólico da mulher no mito:

E agora, porque será a mulher o lugar privilegiado onde se defrontam o interdito e o desejo? Na narrativa bíblica ela representa o ponto de inflexão e de fraqueza diante do sedutor: é através da mulher que a serpente tenta o homem. (p. 273)

Para além do reconhecimento, pelo filósofo, de certo ressentimento muito masculino, que um espírito nietzschiano poderia aliás qualificar como Javista, a interpretação de Ricœur, na medida em que procura ler no mito adâmico uma dimensão existencial do mal que não reduza a finitude humana à condição de mortalidade do homem acaba não podendo evitar a negação do significado literalmente sexual do mito. Ricœur propõe uma leitura simbólica na qual Eva, mais do que ser mulher, representa a mediação da fraqueza humana: "Eva não é, portanto, a mulher enquanto "segundo sexo"; toda a mulher e todo o homem são Adão; todo o homem e toda a mulher são Eva; toda a mulher peca "em" Adão, todo o homem é seduzido “em” Eva." (p. 274)

Ora, se por um lado é certo que, tanto o ser-para-a-morte heideggeriano quanto a denúncia ideológica do machismo da narrativa do Gênesis tendem a reduzir o significado do conteúdo simbólico do mito, por outro lado, a démarche hermenêutica de Ricœur furta-se de indagar, no mito, sobre as razões, originárias ou não, da associação simbólica entre Eva e a fraqueza humana.

Do ponto de vista feminista, no entanto, a interpretação daquilo que é uma inquestionada associação simbólica tão presente no imaginário social não pode conduzir, como aliás não conduz, às mesmas atualizações de leitura. Ou seja, da mesma forma que, segundo o próprio Ricœur, não podemos acreditar na versão realista do mito, nem na identificação filosófica entre homem pecador e homem mortal, tampouco podemos acreditar que a associação simbólica entre Eva e a fraqueza signifique a ultrapassagem da divisão sexual.

Vista pelo ângulo do pensamento ético feminista, a atitude hermenêutica do filósofo dramatiza-se então. Pois o problema aqui não é conduzir a certo conflito de interpretações para poder reavaliar o valor de verdade dos mitos, o problema é que a dialética do arqueológico e do teleológico acaba ocultando a persistência de uma verdade originária do mito que se sedimenta na própria interpretação dele. Uma verdade que, paradoxalmente, só se revela, porém, no fracasso da dialética. Em outras 
palavras, a revelação de Eva como figura da fraqueza humana esquece que a dimensão simbólica está presente desde a origem na interpretação coletiva da existência histórica da mulher, e que isso faz dela uma causa real e persistente da finitude humana. O ser-para-a-morte objetiva-se na figura da mulher, e não se compreende totalmente nela. A hermenêutica permanece crítica, mas precisa se feminizar através do reconhecimento do caráter quase objetivo do ser mulher.

Como está em $O$ segundo sexo de Simone de Beauvoir (2009), no imaginário social, o ódio à mulher associa-se desde sempre à função materna, ela mesma marcada pelo estigma da mortalidade humana. Isto é, por culpa de ser filho de mãe, o homem não pode ser criatura à imagem de Deus. Daí que a análise interpretativa do papel desempenhado pela figura da mãe em nosso universo simbólico arcaico seja imprescindível para a compreensão do mito adâmico, com a associação, nele inclusa, entre a feminilidade e o mal. Por isso é preciso ler o sentido da mediação da fraqueza em Eva como algo que, finalmente, não pode ser mais do que sexo:

A mãe destina o filho à morte ao dar-lhe a vida; a amante induz o amante a renunciar à vida e a abandonar-se ao sono supremo (...) Nascido da carne, o homem realiza-se como carne no amor e a carne é condenada ao túmulo. Com isso, confirma-se a aliança da mulher com a Morte; a grande ceifadeira é a figura invertida da fecundidade que faz crescerem as espigas. Mas ela se apresenta também como a horrível desposada cujo esqueleto se revela sob a tenra carne mentirosa. Assim, o que o homem detesta e ama antes de tudo na mulher, amante ou mãe, é a imagem imóvel de seu destino animal, é a vida necessária à sua existência, mas que a condena à finitude e à morte. Desde o dia em que nasce, o homem começa a morrer: é a verdade que a mãe encarna. (pp. 238-239)

São evidentes as consequências práticas de uma interpretação que sou tentada a apresentar como hermenêutica do fracasso dramático do conflito das interpretações: daí decorre a compreensão de uma culpa que cristaliza tanto uma servidão simbólica específica quanto uma liberdade moral singular: se as mulheres não mais quiserem ter filhos, a humanidade acaba, e no entanto, elas só podem ter filhos mortais. Elas são, neste sentido, verdadeiramente responsáveis por certa finitude humana que, do meu ponto de vista, não se neutraliza. Em dor darás à luz filhos. Ou não darás. Em decorrência disso, também não me parece tão simples tornar sexualmente neutro o desejo do desejo que para Ricœur se apodera no mito adâmico do conhecer, do querer, do fazer e do ser. Como observa Beauvoir: 
Diz-se, por vezes, "o sexo" para designar a mulher; é porque ela é a carne com suas delícias e seus perigos. Quanto ao fato de, para a mulher, ser o homem o sexual e o carnal, é uma verdade que nunca foi proclamada porque nunca houve ninguém para a proclamar. A representação do mundo, como o próprio mundo, é operação dos homens; eles o descrevem do ponto de vista que lhes é peculiar e que confundem com a verdade absoluta. (p. 211)

Vale então lembrar que a proposta ricœuriana de definição da identidade como ipse - que eu seja eu mesmo(a) - e não como idem que eu permaneça igual - através de uma hermenêutica de si (Soi-même comme un autre) ecoa em Simone de Beauvoir, mais exatamente n'O segundo sexo, no qual a questão da subjetividade também está lidando com todas as esferas possíveis da objetivação do sentido - corpo, desejo, crenças, símbolos, linguagens, obras, história. Porém a passagem pelas objetivações não garante por si só a verdade de sua interpretação. Em Beauvoir, a mulher por construir é uma tarefa hermenêutica a partir de uma dialética da distanciação dos mitos do feminino e da reflexão fenomenológica a partir da divisão dos sexos. Em Ricœur, a tarefa hermenêutica apoia-se numa distanciação dos arcaísmos da divisão sexual para produzir a reflexão hermenêutica sobre o mal, mas o sujeito por construir não pode ser mulher.

Neste sentido, entre a hermenêutica crítica de Ricœur e a literatura de mulher, as relações prometem ser mais complexas do que uma análise baseada apenas no conceito de identidade narrativa levaria a crer. Deve haver certo jogo de resistência a cada vez que se introduz a própria hermenêutica crítica feminista como termo mediador fundamental. Torna-se útil mostrar que a teoria feminista há muito vem se pensando também em sua tarefa hermenêutica, e eu diria inclusive que ela sempre foi e só pôde ser uma tarefa hermenêutica crítica - ou seja, uma tarefa de compreensão existencial e não de explicação objetiva, mais além disso uma tarefa que desde sempre se valeu da dialética do distanciamento e da apropriação das objetivações do feminino que a história produz.

Do famoso on ne naît pas femme, on le devient ao esvaziamento radical que a teoria queer impôs ao conceito de feminino, através de sua recusa de uma articulação fenomenológica entre sexo e gênero ${ }^{6}$, a qual desemboca na famosa tese da paródia de gênero e da performance da

\footnotetext{
${ }^{6}$ Quais são as categorias que nos permitem ver? Quando nossas percepções culturais enraizadas no cotidiano fracassam, quando não se consegue ler com segurança o corpo que se vê é quando precisamente não se sabe ao certo se o corpo percebido é o de um homem ou o de uma mulher. (traduzido por mim a partir de Trouble dans le genre, 1999, p. 46)
} 
identidade, persiste sempre uma prática altamente fiel ao princípio da relação com objetivações. Mas o problema é a escolha delas. Beauvoir e Butler são duas hermeneutas em conflito da teoria feminista, a primeira insistindo na crítica das ideologias a partir de uma situação feminina que inclui também uma análise fenomenológica do corpo sexuado, e a segunda preocupando-se com a hermenêutica de desconstrução dos esquemas de poder, que inclui a própria negação de uma fenomenologia do corpo, no qual se suspeita que se inscrevam passivamente as marcas normativas do poder.

Para Nancy Fraser, a questão do feminismo, pragmática, situa-se sempre num espaço discursivo coletivo, e precisa permitir negociações políticas emancipadoras que não podem e não devem se perder em considerações arriscadas sobre a natureza individual da feminilidade.

Neste sentido, se as teorias feministas reconhecem para si, há muito, a tarefa de construção de um espaço de conflito de interpretações fomentado por elas mesmas, a questão interessante é a de saber o que exatamente, além do conceito de produtividade do conflito hermenêutico, o projeto de hermenêutica crítica de Ricœur pode trazer para o debate sobre a escolha dos objetos. Isto significa sobretudo que o pensamento feminista deve produzir por si mesmo uma tarefa de hermenêutica crítica em relação à própria filosofia de Ricœur.

Quero aqui tomar um exemplo que ajude a esclarecer minha argumentação, ainda com Nancy Fraser (2012): num artigo magistral intitulado $\mathrm{O}$ que tem de crítica a Teoria crítica? O caso de Habermas e do gênero (pp. 31-74), a autora denuncia certos postulados da Teoria do agir comunicativo. A verdade de uma boa teoria crítica não é meramente epistemológica, e sim política - eis o ponto de vista realmente feminista, diz ela. Assim que, a proposta de trazer para o campo da vida política em comum uma estrutura de tipo transcendental, suscetível de acolher quaisquer projetos de cidadania, desde que enquadrados pelo esquematismo da negociação democrática enquanto pura forma prática da política, como é o caso de Habermas, pode ocultar verdades políticas nada formais e nada transcendentais. O caso de Habermas relido por Nancy Fraser é paradigmático: pois ele, aparentemente, teve a preocupação de proteger a função cidadão contra as contaminações patológicas e as influências individualistas do capitalismo, alegando que o simbólico é de todos, e por isso não se vende. 
Quem não concordaria? Ora, rebate Nancy Fraser, uma vez que todo o edifício habermasiano assenta-se na necessidade normativa de separação de duas esferas culturais, a da reprodução material e a da reprodução simbólica, há que se objetar que esta separação serve à reprodução da ideologia androcêntrica, pois a tarefa de criar filhos, que segundo Habermas não pode cair nas garras da lógica mercadológica do capitalismo tardio e precisa ser protegida pela aura do simbólico, significa concreta e politicamente a opressão das mulheres.

A conclusão de Fraser é a seguinte: o postulado de que criar filhos seja tarefa simbólica é empiricamente falso (pois é, também, uma tarefa material) e ideologicamente perigoso. Do ponto de vista da ética da emancipação das mulheres, a teoria de Habermas não resolve o problema do reconhecimento simbólico delas, justamente por confiná-las na tarefa simbólica de criar filhos. Implicitamente, Habermas estaria sugerindo que a saúde do sistema democrático depende do fato que as mulheres passivamente aceitem as vicissitudes e os deveres éticos que decorrem de sua posição materna.

E Nancy Fraser convida à conclusão: o feminismo não pode sucumbir ao charme de nenhum pensamento que pretenda à neutralidade do gênero, e isto inclui a suposta neutralidade dos conceitos, da linguagem e dos textos. Nesta medida, pelo prisma da argumentação pragmática de Nancy Fraser, se é certo que existe empiricamente um discurso individual, é certo também que não é neste plano que encontraremos uma linguagem transformadora. Se, diz ela ainda em outro artigo (2012, pp. 191-215), das duas metades divididas do sujeito de Kristeva nenhuma pôde se tornar um agente político feminista, é porque nenhuma subversão é possível no plano de uma dialética individual. E, no caso da Kristeva, o resultado é que as mulheres vão ser mães, enquanto os homens vão escrever poesia de vanguarda, cada um tendo com o semiótico uma relação psicótica diferente.

Como vemos, certa ocultação da questão da divisão sexuada, através da valorização e da preservação do valor universal do simbólico, opera de modo semelhante em textos muito diversos. O que me leva a concluir que uma hermenêutica crítica como a de Ricœur precisa ser posta à prova da ressignificação sexual por certa hermenêutica crítica feminista. 


\section{FAZENDO UMA LEITURA HERMENÊUTICA CRÍTICA FEMINISTA DA HERMENÊUTICA CRÍTICA DE RICCEUR}

Para me concentrar agora no problema específico de reflexão sobre a leitura dos textos de literatura, formularei então duas perguntas. Primeiro, como tratar pela mediação da hermenêutica crítica feminista o conceito ricœuriano de texto, definido por Ricœur como algo objetivo e de configuração estável? Segundo, como lidar, pelo ângulo da mediação feminista, com a tarefa hermenêutica ricœuriana de escolher uma interpretação, uma vez que a tarefa é assumida pelo filósofo como necessidade prático-poética, embora do ponto de vista feminista escolher dramatize sempre um já ter escolhido?

Em outras palavras, como lidar com fato que a hermenêutica feminista não possa nem ficar em nem sair do círculo hermenêutico?

Num primeiro momento, tomemos aqui que a medula da hermenêutica crítica de Ricœur é - como demostra Hélio Salles Gentil no livro Para uma poética da modernidade (2004) -, a existência do texto. Isto supõe, como está em Du texte à l'action (1986), uma série de decisões, as quais definem a hermenêutica crítica de Ricœur antes de tudo como um processo de distanciamento do texto enquanto condição de sua apropriação e interpretação.

Para além do discurso, no texto, de fato, o que se diz não se esgota no contexto da comunicação; algo subsiste, aoalém, (e sob forma deveemência ontológica). Desta maneira, a confiança na existência do texto é o que garante paradoxalmente que possamos nos afastar dele, ao mesmo tempo que é também por causa e através da existência textual que podemos nos aproximar da realidade, uma vez que a referência metafórica, a qual está no texto, projeta justamente ao além de seu contexto um mundo possível e imaginável, apontando então para um mundo realizável. Como diz ainda Hélio Salles Gentil, este ponto de partida para uma dialética do evento e da significação existe porque o texto é um escrito: a significação se destaca, se transmite no tempo, interpõe-se à crença romântica nas intenções do autor. Da sua autonomia à entrada numa relação com outros textos que venham a tomar o lugar da realidade circunstancial, formando com eles o quase-mundo da literatura, o processo do texto dá-se por distanciamento crítico, e pede um trabalho de leitura, que é de descontextualização e recontextualização. 
Uma vez admitida a existência do texto onde tem lugar um tipo de acontecimento da significação, podemos nos distanciar novamente dele através do exercício de nossa faculdade crítica, por exemplo, fazendo a crítica dos valores que no texto podem ter se cristalizado, e desaceitando receber o texto como um bloco monolítico de verdades definitivas. E entre as vantagens do texto, temos ainda o fato que não ter o texto pode significar correr o risco de se perder na mitologia do paratexto, no empirismo do arquivo, na subjetividade positivista do não texto. Cartas, entrevistas, depoimentos: o que eles dizem da literatura? E o que ela, sendo texto, pode dizer que eles já não digam? O reconhecimento da existência do texto por Ricœur pode, portanto, servir para estabelecer o valor estético da literatura.

Entretanto, o caráter problemático da existência do texto, tal como ela é tematizada por Ricœur, não se encontra no fato que haja objetos, chamados textos, aos quais se apliquem nossas críticas de valores. Claro que, neste estágio de definição do texto, a própria retórica (da ficção, do autor, do leitor) sabe e deve lidar com a ideia de configuração do texto, e logo com a existência, ainda que apenas empírica, dos textos. Porém, inversamente, o problema é que o texto em geral possa ser ele mesmo transformado em conceito de texto por um discurso filosófico que deduz diretamente, sem a mediação, de fato impensável, de todos os textos, um valor existencial do texto em si. Se levarmos em consideração que Ricœur foi particularmente sensível à diversidade dos textos, esta atitude pode soar como um paradoxo. Ricœur enfrenta essa dificuldade em dois momentos distintos de Tempo e Narrativa, e provavelmente com dois objetivos diferentes.

1)No capítulo 4 de Tempo e Narrativa 3, o problema é o do reconhecimento da qualidade estética e da transmissão dos valores éticos e poéticos pelo texto. Tudo se passa então como se o texto coincidisse com seu próprio modelo. Assim como Homero cria um modelo de ação heroica ao narrar ações heroicas, o texto criaria a ideia de texto apenas porque é um texto.

Neste preciso ponto, a questão da hermenêutica crítica feminista pode operar um desdobramento crítico, distanciando-se de Ricœur, pois pelo ângulo do feminismo, é justamente o distanciamento do texto onde se afirma o valor em si do texto (ou seja, Ricœur à la suite de toda a escola estruturalista) que se faz necessário. Trata-se para a leitura feminista de refletir sobre as condições de possibilidade da autoridade do texto 
canônico literário em si. Em contraponto, revela-se, à leitura de Ricœur, que o distanciamento do texto, requerido pelo próprio filósofo como condição de qualquer interpretação, fundamenta-se, em suma, numa postulação prima da veemência ontológica do texto em si enquanto fonte de autoridade superior à de um mero discurso. Ora, de onde provém essa afirmação de autoridade? (posto que, é claro, ela nãovem do texto: nenhum texto é capaz de afirmar com veemência ontológica sua própria existência e muito menos sua própria autoridade). E a conclusão só pode ser que, assim como a autoridade do modelo de ação heroica de Homero originase na tradição, a autoridade da ideia de texto como valor em si originase também numa tradição. Sem a ideia de tradição não se sustentaria a retomada do trabalho de descontextualização numa recontextualização. Ora, este trabalho não deixa de ser problemático para a crítica feminista quando, no processo de descontextualizar, certas normas exógenas ao texto resgatam-no para um acervo comum onde se definem ao mesmo tempo a forma e o conteúdo da veemência ontológica.

Neste sentido, a operação de distanciamento do texto precisa discutir também o texto enquanto conceito questionável em si, tomando como ângulo de discussão a política filosófica e literária que está por trás do conceito de texto.

Examinemos, por exemplo, a famosa fórmula: explicar mais para compreender melhor: ela introduz problemas de porte. De fato, ao mesmo tempo que Ricœur pretende que a configuração textual estabelece e delimita um texto $x$, no entanto as regras de configuração de um texto (ou seja, a composição da obra, o pertencimento a um gênero, o estilo individual) não são legíveis como tais no próprio texto, enquanto acontecimento absolutamente singular. Por isso mesmo, no referido capítulo Mundo do texto, mundo do leitor, este problema de configuração precisa tornar-se um problema de recepção, isto é, de certa decisão que recai in fine sobre o leitor. Ora, se, para Ricœur pode haver, por um lado, certa singularidade de leitura no ato dela (pelo ângulo da fenomenologia da leitura), por outro lado, não há singularidade absoluta da configuração de um texto, mesmo para um leitor. Do contrário, não poderia haver nenhum reconhecimento do valor da obra. Toda a questão da interpretação literária em Ricœur passa pelo esquematismo da aplicabilidade de modelos estranhados e reconhecidos. A configuração textual ricœuriana, no fundo, supõe formas que são históricas e transhistóricas, e o processo de individuação dá-se somente em relação a 
um modelo estético, ainda que seja para subvertê-lo. Como ele mesmo diz: obras que subvertem o gênero ainda têm como referência os paradigmas constitutivos do próprio gênero, do contrário não seriam subversivas.

Este reconhecimento do valor da tradição não é, claro, uma adesão aos valores tradicionais, mas não deixa de ocultar sua origem enquanto decisão sobre o valor textual. Atrelada à questão da configuração, o que a recepção precisa fazer não é explicar o texto, e sim compreender como ela mesma justifica sua adesão ao texto. Inversamente, explicar por que um texto entrou para o cânone deixa de ser um problema de configuração, e passa a ser de crítica ideológica ou estética. A ação de compreender o texto, no sentido de vivenciar valores não consegue se distanciar da ação de reconhecer que tais valores precisam da autoridade do texto enquanto texto. No entanto, na prática, posso querer os valores e não querer a autoridade do texto em si. Posso não reconhecer a autoridade da configuração e reconhecer valor existencial no ato de leitura do texto. Nada, na dialética do explicar e do compreender, me obriga a aceitar a autoridade do texto enquanto texto como condição de possibilidade do acesso a seus valores. Meu trabalho de leitura pode ser um ato altamente desconfigurador e não ser um ato de rejeição de valores. $\mathrm{O}$ que significa claramente que nada me obriga a conceder o estatuto de objetividade à configuração textual. Nada tampouco obriga-me a lidar com a totalidade textual da narrativa, realizando sua compreensão e aplicação apenas como síntese de leitura, isto é, depois de saber o começo meio e fim da narrativa.

A adesão ao texto em si faz parte de uma louvável política de defesa da narrativa, mas encontra sérias dificuldades quando se defronta com a literatura de mulher.

\footnotetext{
"As mulheres e as crianças são as primeiras que

desistem de afundar navios”. (Ana Cristina Cesar - A teus pés, 1998, p. 46).
}

Isto é um texto? O poema, chamado Cartilha da cura, propõe a cura. Mas cura de quê? Do texto, certamente. De onde infiro que o quase-mundo da literatura não é apenas um mundo de textos, ainda que seja um mundo de compreensão dos valores dos textos. Inclusive, o próprio discurso sobre o que é um texto pode mudar, como de fato mudou.

2) Ricœur enfrenta diversamente a mesma questão do texto em Tempo e narrativa 2, capítulo 2 , dedicando-se a uma discussão com teóricos estruturalistas, eles mesmos postos em discussão dialeticamente, como é 
próprio do seu método hermenêutico crítico. Nesta discussão, já ao final da argumentação ricœuriana, o modelo semiótico radical de Greimas surge inesperadamente como a solução mais válida para uma teoria hermenêutica da leitura. O modelogreimasianoéum sistema de explicação que deixa voluntariamente de fora do famoso quadrado semiótico aquilo que a teoria da leitura de Ricœur propõe retomar, e é justamente por isso que o filósofo o julga aproveitável. O transcendental da compreensão narrativa, que não é de modo algum a cronologia propriamente dita das narrativas textuais enquanto sucessão de fatos, e sim a própria estrutura de temporalidade de toda narrativa, é precisamente o grande achado de Ricœur que, segundo ele mesmo diz, ficou de fora da semiótica.

Ora, no entanto, a metatextualidade da semiótica é evidente, e por isso mesmo ela nunca explica o texto. Mas aqui, o problema da posição ricœuriana é outro: ao lidar com significações, a semiótica paradoxalmente interrompe o processo temporal de interpretação da significação, e tudo se passa como se o leitor interpretante não existisse para a análise semiótica. Fica difícil pensar como então esta mesma semiótica pode fazer o que faz, isto é, interromper (ou suspender, como diz Ricœur) um processo temporal apenas no interior do texto, sem que haja também uma anulação do tempo fora da narrativa, no plano crítico e filosófico. Pareceme portanto que o projeto de retomar o processo onde Greimas o deixou, a fim de compreender o texto depois da semiótica tê-lo explicado, é algo que simplesmente não pode ocorrer a não ser como decisão concreta e portanto temporalizada de anulação da anulação temporal por um sujeito leitor: afinal, o leitor que toma a decisão de compreender um texto narrativo como narrativo (isto é, pelo ângulo de sua estrutura temporal) nada alcança conservar do modelo explicativo de significação de Greimas. A explicação estrutural do fenômeno de significação por Greimas é exclusiva e postula que não se explica a significação do texto sem explicar totalmente a significação, ou sem esgotar a significação. A semiótica, como seu nome não diz, não é semi-ótica e por isso mesmo ela é toda a ótica, e não deixa restos a compreender. Dizendo ainda de outro modo, o sujeito interpretante da semiótica compreende-se necessariamente como alguém que não pode ter nada a compreender, do contrário não faria análise semiótica. Mas o que podemos talvez inferir lendo Ricœur pelo ângulo dos ensinamentos de sua própria hermenêutica crítica (e pelo ângulo da tese do necessário conflito de interpretações concorrentes como condição fundamental da compreensão) é que talvez não exista 
em Ricœur nenhum projeto de aproveitamento de Greimas, e sim, para quem souber ler, uma intenção de ultrapassagem radical, e finalmente de abandono do modelo semiótico.

Esta crítica à adesão de Ricœur ao conceito de texto em si enquanto configuração ou veemência ontológica faz-se com argumentos críticos, mas vale lembrar que, no campo da reflexão sobre o estatuto do texto, o drama da ocultação do feminino surge redobrado, pois não só é discutível que o valor conceitual do texto de ficção possa provir de um discurso paralelo onde se estabelece a verdade do texto (por exclusão de outras práticas discursivas), como também é discutível que se possa chegar a algum estatuto neutro do conceito de texto (por esvaziamento de seu significado androcêntrico). É de se notar que as melhores e mais radicais críticas ao estruturalismo tenham sido fruto do pensamento feminista, cujos argumentos poderiam perfeitamente cimentar um debate filosófico, mas que no entanto parecem passar despercebidos. De fato, apenas o feminismo mostrou a coerência prática da solidariedade entre o pensamento androcêntrico que se diz numa determinada linguagem e o pensamento da linguagem que é fruto de uma prática androcêntrica. Gayle Rubin (2010) e Monique Wittig (2006) mostraram, ambas, a conivência violenta de Lévi-Strauss e Lacan, apontando para o fato que tanto a troca de mulheres em Lévi Strauss elege um dado empírico à condição de transcendental da cultura, quanto o domínio do simbólico fálico de Lacan contribui para a conformação das crianças à sua heterossexualidade obrigatória. Ou como diz Wittig: "Para mim não há a menor dúvida que Lacan tenha encontrado no inconsciente as estruturas que ele diz ter encontrado, uma vez que ele primeiro as pôs lá dentro" ( $\mathrm{La}$ pensée Straight, 2006, p. 59)7. É assim também que fazemos um texto: ocultando que ele não é mais que uma interpretação a ser negociada no espaço comum.

${ }^{7}$ Traduzido por mim. 


\section{NECESSIDADE DA RESISTÊNCIA DA LITERATURA PARA A HERMENÊUTICA CRÍTICA}

Passo então à minha segunda questão: observar os efeitos práticopoéticos produzidos pela literatura quando lida pelo ângulo de uma hermenêutica crítica.

Mas começo por um desvio filosófico: No magistral Prefácio de Si mesmo como um outro, Ricœur afirma que, se por um lado o cogito cartesiano não possui nenhuma significação filosófica forte se sua posição não estiver habitada por certa ambição de fundação última, por outro lado o anti-cogito de Nietzsche não deve ser visto como o inverso do cogito cartesiano, e sim como um aprofundamento hiperbólico da dúvida hiperbólica de Descartes. Situando com originalidade Descartes e Nietzsche na mesma esteira de certa confiança na desconfiança, Ricœur conclui: a desconstrução nietzschiana vem a significar apenas duvido melhor que Descartes. O próprio cogito é duvidoso. Se cogito e anti-cogito podem com essa destreza ser ultrapassados, é que de certa forma foram ambos objetivados em sua própria dimensão textual - o texto de Descartes e o texto de Nietzsche lidos por Ricœur. O método é magistral.

O que poderíamos fazer então, a exemplo de Ricœur, com o texto de Ricœur?

Fico com dois exemplos particularmente significativos para uma hermenêutica feminista. O primeiro está em Da interpretação. Ensaio sobre Freud, capítulo IV.

O ensaio, dedicadoa uma reflexão sobre Freud, termina com o capítulo intitulado "as abordagens do símbolo", onde se avaliam as possiblidades de resolução dialética de um conflito hermenêutico, legado fundamental da psicanálise em seu trabalho de descoberta do duplo sentido da linguagem e da significação inconsciente de nossos discursos.

Se, formalmente, a solução para esse problema de divisão pelo símbolo já se encontra formulada por Ricœur - ela será uma dialética do arqueológico e do teleológico - é ainda preciso encontrar, daí o capítulo, o misto concreto no qual leremos, um sobre o outro, o arqueológico e o teleológico. Este misto, como logo saberemos também, será o próprio símbolo, mas agora analisado como enigma, por sua natureza polissêmica, a ser desvendado dialeticamente. No símbolo, articulam-se a monotonia de conteúdo dos sonhos (que todos dizem a mesma coisa) e a abundância das representações, e é desse segundo nível polissêmico que será preciso 
dar conta. Fato que irá demandar uma dialética do símbolo, não apenas definido como discurso do inconsciente ou trabalho do sonho, mas também como trabalho de cultura.

A hermenêutica crítica de Ricœur revela aqui sua potência: a presença do conflito de interpretações é reconhecida como legado freudiano que é preciso alçar a certo plano superior do conflito, onde possam ser convocados também tanto o texto concorrente da hermenêutica de Hegel quanto o texto de Sófocles - Édipo-rei. Com eles se produz uma leitura dialética, ela mesma por sua vez produtora de um novo texto - de Ricœur -, onde se lê (e é o que estou fazendo) outra interpretação da tragédia de Sófocles (que Ricœur define como exemplo exemplar), e com esta outra interpretação formula-se então uma nova concepção do símbolo (que de certa forma já estava implicada nas leituras anteriores, como lei do círculo hermenêutico).

Apenas proponho aqui discutir a interpretação ricœuriana da obra de Sófocles como obra de cultura (parte 3 do capítulo, intitulada Retomada dialética do problema da sublimação e do objeto cultural) à luz de minha própria hermenêutica feminista.

Como observa Ricœur, Freud recusa que a obra de Sófocles seja e signifique uma tragédia do destino (isto é, a representação do contraste entre a onipotência dos deuses e a vaidade do esforço humano alquebrado pelo fado inelutável).

O que nos comoveria na Tragédia, segundo Freud? A maldição da fantasia arcaica, cujo castigo aterrorizante, incluso no conteúdo da obra, significa a violência do nosso próprio recalcamento contra a revivescência do desejo infantil incestuoso e parricídio.

Não devemos menosprezar a indignação de Ricœur quanto à maneira desenvolta de Freud, para quem o resto não passa de equívoco e elaboração secundária, no tratamento da interpretação teleológica da obra enquanto conflito da Providência e da liberdade.

É justamente esta lacuna que o motiva, segundo suas próprias palavras, a lhe objetar uma segunda interpretação: o segundo drama, diz ele, é a tragédia da consciência de si, a tragédia da verdade que engendra outra culpa, a de não se reconhecer como responsável pela peste e pelo crime, a de precisar ser vencido, em seu orgulho, pelo sofrimento. E já não é mais o desejo culposo da criança que está então em jogo, e sim o orgulho do rei adulto. Paixão impura, em relação à verdade, que aproxima a hybris de Édipo da de Prometeu. Falta que já não se localiza na libido, 
e sim na consciência de si faltosa. Édipo, esta é uma verdade, torna-se culpado pela pretensão de se desculpar por um crime que eticamente, de fato, não cometeu.

E Ricœur conclui que se a esfinge representa, na obra, o inconsciente, o vidente Tirésias está do lado do espírito. Isso explica que Édipo-rei, cego sobre si mesmo, só se torne consciente de si tornando-se ele mesmo vidente-cego. O aviso final: vejam Édipo, adivinho de enigmas famosos, quem não o invejaria? E agora, em que corrente terrível de infortúnios ele está imerso! O aviso fere nosso orgulho de adultos sabedores e poderosos.

Daí que o símbolo, enquanto objeto cultural, é a unidade profunda do travestimento e do desvelamento.

Atenho-me aqui: Ricœur refere-se a Tirésias como vidente, como representante do espírito na interpretação teleológica da tragédia de Sófocles enquanto drama da verdade. Mas a vidência de Tirésias é também uma ocultação de segundo grau. Pois como se lê em Ovídio, numa passagem que não cessa de me assombrar simbolicamente (Metamorfoses III/317-352), a vidência de Tirésias é resultado de uma elaboração narrativa, isto é, de uma história da vidência. No mito, ao perturbar numa floresta a copulação de um casal de serpentes com um cajado, Tirésias será metamorfoseado em mulher. Sete anos depois, ao cruzar com uma situação semelhante na mesma floresta, toma a decisão, baseado em seu pensamento mágico, de fazer o mesmo gesto, com a finalidade, obviamente, de desfazer a metamorfose. Com êxito. A sabedoria prévia de Tirésias não tem inicialmente qualquer caráter trágico. Contudo, intimado por Juno e Júpiter a se pronunciar sobre os graus de intensidade do prazer sexual do ponto de vista de sua vivência dual, Tirésias revela então uma verdade (que a mulher tem mais prazer) a qual, posta em paralelo com sua decisão existencial de tornar a ser homem, aparece claramente como uma contradição. Isto é, como outra forma de conflito hermenêutico que jamais cessou de atormentar a humanidade, e com outro drama do cogito brisé que vige entre os sexos: o drama que imprime ao espírito e ao discurso racional a fatalidade de ter que responder e não poder totalizar; o drama de uma escolha pela verdade que traz sempre uma mentira sobre a escolha. O que Tirésias escolhe dizer é o contrário do que ele escolhe fazer. E como fica, neste caso, a compreensão de si pelo ângulo da escolha hermenêutica? Não se compreende, a não ser como coerência da falácia androcêntrica ou como fracasso da lógica da dialética subjetiva. 
Punido de cegueira por Juno, e redimido com o dom de vidência por Júpiter, Tirésias é na realidade o outro misto concreto, ao lado da obra de Sófocles, onde se lê, através da interpretação cultural da polissemia do símbolo, o fracasso de uma dialética racional, a qual, posta à luz da ocultação do drama de uma escolha pelo feminino, obriga a percorrer os corredores do tempo por outras vias que não a lógica das articulações entre o arcaico e o teleológico. Pois quem poderia dizer em que esfera se oculta o drama da ocultação, quando o próprio drama se dissemina na divisão das esferas?

O dom de profecia hermenêutica também em geral oculta seu drama feminino de escolher: finja sempre que o prazer da leitura, afirmado em grau máximo, condiz perfeitamente com suas compulsões críticoracionais sem explicá-las enquanto escolha. Não assuma na linguagem o prazer, para poder não assumir a mentira. À tragédia da verdade, some-se o drama do prazer de mentir.

Disto também se infere que a hermenêutica dos símbolos enquanto objetos culturais talvez jamais se desimplique do emaranhado quasetextual, entre mítico e literário: deslocar o drama da verdade para o lado da teleologia que Freud não viu é também esquecer o drama da mentira que ele contou. Pois quem poderia afirmar que o complexo de Édipo não é uma grande mistificação cultural, marcado pela tragédia edipiana de acabarmos acreditando em Tirésias?

Felizmente, a narrativa ovidiana não pertence ao rol dos acontecimentos trágicos, e o poeta latino enceta lembrando: enquanto ocorrem na terra esses acontecimentos regidos pela lei do destino... Enquanto isso... Foi este, quero dizer, o tempo do enquanto, paralelo ao da ação configurada, que Ricœur evitou interpretar.

Enquanto isso, quase-textos de mulheres adotam claramente a estratégia política da prescrição contraditória (o termo é meu) e do emaranhado textual como forma de interpretar o antigo drama da escolha. Textos nos quais a própria interpretação se torna também um drama da escolha: afinal, aquele cego mascando goma do conto Amor de Clarice Lispector revelou à personagem Ana, mas revelou o quê? O prazer mudo que o tornou cego porque ele confessou, mentindo? Se o nada da revelação me oculta tanto quanto qualquer resposta, inclusive o gozo, resta-me então? Talvez o detalhe de um estouro de fogão, que não ocorre; um marido que não morre, e uma mise en abîme elegante da prescrição 
contraditória, quando Ana, vibrante, afirma: não quero que lhe aconteça nada, nunca! O detalhe insignificante que não produziu tragédia, porque não aconteceu e não foi escolha...

Passo rapidamente ao segundo exemplo: Septimus, quanto a ele, escolheu como um homem e se matou... mas o que Ricœur - extasiado com a riqueza da imaginação estrutural de Virgínia Woolf em Mrs Dalloway (Tempo e narrativa 2, capítulo 4: A experiência temporal fictícia) - não viu é que Richard não tinha graça, que Mrs Dalloway é o drama feminino da escolha (entre heterossexualidade e homossexualidade, entre dois maridos e entre dois maridos ou marido nenhum). Não é Big Ben que estrutura a narrativa em Mrs Dalloway, é a representação dos enquantos femininos que, justamente, nada estruturam porque nada escolhem. Mas o êxtase que acompanha esse processo hermenêutico de enquantamento subsiste apenas, é verdade, nas diversas formas de configuração narrativa temporal. Neste sentido, Ricœur prepara muito utilmente a representação do drama feminino da escolha, mas não o vê e não o interpreta porque não o imagina.

E para voltar então, pelo ângulo da literatura de mulher, à questão do texto, agora vinculada ao drama da escolha e ao tema da imaginação:

Enquanto leio meus seios estão a descoberto. É difícil concentrar-me ao ver seus bicos. Então rabisco as folhas deste álbum. Poética quebrada pelo meio.

Enquanto leio meus textos se fazem descobertos. É difícil escondê-los no meio dessas letras. Então me nutro das tetas dos poetas pensados no meio seio.

diz um lindo poema de Ana Cristina Cesar (Inéditos e dispersos, 1985, p. 92)

Devo escolher entre texto e sexo? Devo escolher entre ler e escrever? Devo escolher entre esconder e revelar?

Mais uma vez e para concluir, obviamente a hermenêutica feminista precisa dizer que sim e que não. Precisa dizer que não devo escolher, a fim de iluminar pela atitude hermenêutica a polissemia simbólica da representação literária e do drama feminino que há em escolher. Mas precisa, enquanto isso, continuar afirmando que falar de hermenêutica feminista é, justamente, escolher.

Se, através da teoria da leitura, podemos procurar pelo avesso, como ausência, similitudes entre as resistências do feminismo à universalização filosófica e as resistências do literário à teorização, provavelmente que uma 
hermenêutica crítica feminista tanto há de concordar com a ideia de que o tempo seja uma estrutura transcendental da compreensão dos textos e de si, quanto há de recusar que esta ideia seja justa para com o drama da escolha. Em Ricœur, a hermenêutica literária corre ad infinitum por causa mesmo da necessidade ética de decisão. É bonito, mas talvez não tenha sido pensado o suficiente o estatuto incomprimível, próprio de ser levado em consideração por uma hermenêutica crítica, do acontecimento daquele quase-texto cujo gênero é viver nesse estado crítico de quasenarrativa que dramatiza a escolha e problematiza a ética.

Num conto de sua autoria que a autora provocativamente declara não compreender - O ovo e a galinha - de Clarice Lispector (1971, pp.49-59), a quase estrutura narrativa (isto é, o caráter insignificante da sucessão de quadros do ovo) não chega a configurar uma ação, e chama a interpretação temporal para outro campo, sob forma de provocação da leitora.

"Ver o ovo é impossível, o ovo é supervisível. (...) E como poderia a galinha se entender se ela é a contradição de um ovo? (...) A galinha é sempre a tragédia mais moderna".

Alguém explica?

Qualquer escolha hermenêutica aqui reencena o drama de Tirésias no feminino: se você não viu que o ovo é feminino, não viu nada. Se não viu que o ovo problematiza a decisão de ver o feminino, também não viu nada. Porém, ao contrário do que ocorre com a hermenêutica do texto de filosofia que propõe certo nível conceitual de interpretação dos símbolos, na literatura, a síntese do escolher e do não escolher permanece sempre suspensa a uma questão de imaginação.

\section{REFERÊNCIAS BIBLIOGRÁFICAS}

BEAUVOIR, Simone. O segundo sexo. Tradução Sérgio Milliet. Editora Nova Fronteira, Rio de Janeiro, 2009.

BUTLER, Judith. Trouble dans le genre. Le féminisme et la subversion de l'identité. Traduction Cynthia Kraus. Editions La Découverte, Paris 2006.

CESAR, Ana Cristina. A teus pés. Editora Ática, São Paulo,1999.

CESAR, Ana Cristina. Inéditos e Dispersos. São Paulo: Editora Brasiliense, 1985.

COSTA, Cristina H. Imaginação, leitura e crítica. In O Duplo estado da poesia. Modernidade e contemporaneidade. SCRAMIM, Susana, SISCAR, Marcos, PUCHEU, Alberto (orgs.). São Paulo. Editora Iluminuras, 2015. 


$$
418 \text { - Remate de Males } 35.2
$$

FRASER, Nancy. Le Féminisme en mouvements. Des années 6o à l'ère néolibérale. Paris : Editions la Découverte, 2012.

FRASER, Nancy. Structuralisme ou pragmatique? Sur les Théories du discours et la politique féministe. In Le Féminisme en mouvements. Des années 6o à l’ère néolibérale. Paris : Editions la Découverte, 2012.

HABERMAS, Jürgen: Teoria do agir comunicativo. São Paulo. Editora Martins Fontes 2012 JAUSS, Hans Robert. Pour une esthétique de la réception. Paris: Gallimard, 1978.

LISPECTOR, Clarice. Felicidade clandestina. Rio de Janeiro. Editora Rocco, 1971.

OVÍDIO: Les métamorphoses. CHAMONARD, J. (Traduction, introduction et notes). Paris. Flammarion, 1966.

RICEUR, Paul. De l'interprétation. Essai sur Freud. Paris : Editions du Seuil, 1965.

RICEUR, Paul. Le conflit des interprétations. Essais d'herméneutique I. Paris : Editions du Seuil, 1969.

RICEUR, Paul. A simbólica do mal. Tradução Hugo Barros e Gonçalo Marcelo. Edições 70, Lisboa, 2013.

RICEUR, Paul. Du texte à l'action. Essais d'herméneutique II. Paris : Editions du Seuil, 1986.

RICEUR, Paul. Tempo e Narrativa 2. Tradução Márcia Valéria Martinez de Aguiar. Martins Fontes, São Paulo, 2010.

RICEUR, Paul. Tempo e Narrativa 3. Tradução Cláudia Berliner. Martins Fontes, São Paulo, 2010.

RUBIN, Gayle. Surveiller et jouir. Anthropologie politique du sexe. Paris, EPEL, 2010.

SALLES GENTIL, Hélio. Para uma poética da modernidade. Edições Loyola, São Paulo, 2004.

WITTIG, Monique. La pensée Straigt. Editions Amsterdam, Paris 2006. 